San Jose State University

SJSU ScholarWorks

Master's Theses

Master's Theses and Graduate Research

1994

\title{
The relationship of knowledge and attitudes of home care nurses towards clients with aids
}

Elizabeth Manzo Johnson

San Jose State University

Follow this and additional works at: https://scholarworks.sjsu.edu/etd_theses

\section{Recommended Citation}

Johnson, Elizabeth Manzo, "The relationship of knowledge and attitudes of home care nurses towards clients with aids" (1994). Master's Theses. 764.

DOI: https://doi.org/10.31979/etd.rgh8-4et7

https://scholarworks.sjsu.edu/etd_theses/764

This Thesis is brought to you for free and open access by the Master's Theses and Graduate Research at SJSU ScholarWorks. It has been accepted for inclusion in Master's Theses by an authorized administrator of SJSU ScholarWorks. For more information, please contact scholarworks@sjsu.edu. 


\section{INFORMATION TO USERS}

This manuscript has been reproduced from the microfilm master. UMI films the text directly from the original or copy submitted. Thus, some thesis and dissertation copies are in typewriter face, while others may be from any type of computer printer.

The quality of this reproduction is dependent upon the quality of the copy submitted. Broken or indistinct print, colored or poor quality illustrations and photographs, print bleedthrough, substandard margins, and improper alignment can adversely affect reproduction.

In the unlikely. event that the author did not send UMI a complete manuscript and there are missing pages, these will be noted. Also, if unauthorized copyright material had to be removed, a note will indicate the deletion.

Oversize materials (e.g., maps, drawings, charts) are reproduced by sectioning the original, beginning at the upper left-hand corner and continuing from left to right in equal sections with small overlaps. Each original is also photographed in one exposure and is included in reduced form at the back of the book.

Photographs included in the original manuscript have been reproduced xerographically in this copy. Higher quality 6" x 9" black and white photographic prints are available for any photographs or illustrations appearing in this copy for an additional charge. Contact UMI directly to order.

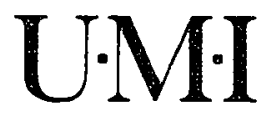

University Microfilms International

A Bell \& Howell information Company 
Order Number 1358188

The relationship of knowledge and attitudes of home care nurses towards clients with AIDS

Johnson, Elizabeth Manzo, M.S.

San Jose State University, 1994 



\title{
THE RELATIONSHIP OF KNOWLEDGE AND ATTITUDES OF HOME CARE NURSES TOWARDS CLIENTS WITH AIDS
}

\author{
A Thesis \\ Presented to \\ The Faculty of the Department of Nursing \\ San Jose State University \\ In Partial Fulfillment \\ of the Requirements for the Degree \\ Master of Science
}

By

Elizabeth Manzo Johnson

May, 1994 
Copyright 1994

Elizabeth Manzo Johnson

ALL RIGHTS RESERVED 
APPROVED FOR THE SCHOOL OF NURSING

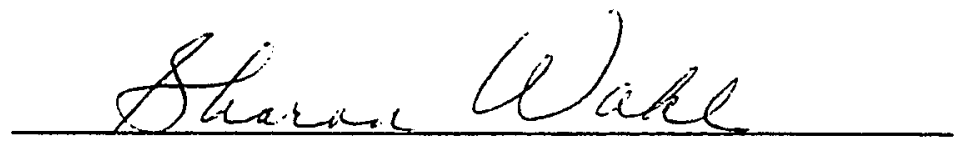
Sharon C. Wahl, Ed.D., R.N.

lerael farane Virgil Parsons, D.N.Sc., R.N.

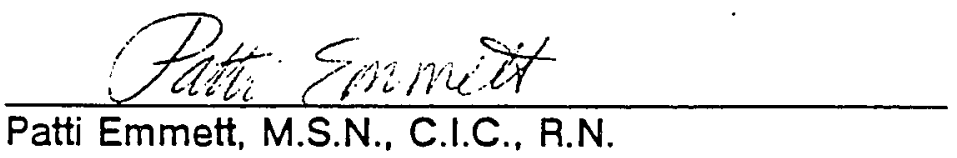

APPROVED FOR THE UNIVERSITY

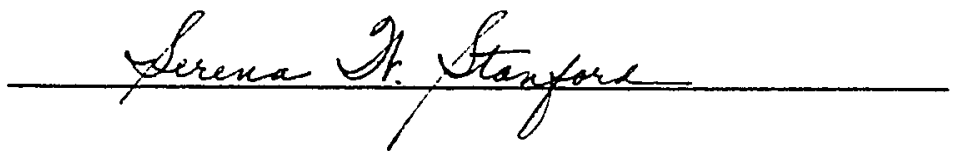




\begin{abstract}
THE RELATIONSHIP OF KNOWLEDGE AND ATTITUDES OF HOME CARE NURSES TOWARDS CLIENTS WITH AIDS

by Elizabeth $M$. Johnson
\end{abstract}

This descriptive thesis studied attitudes of home care nurses towards

clients with AIDS. Data were collected from nurses to determine if knowledge of AIDS affected attitudes and if previous education made a difference in knowledge. The literature suggests that attitudes influence behaviors; therefore, nurses' attitudes may have an effect on the care they give.

The results indicated that the nurses scored $80 \%$ or higher on the knowledge test regardless of their education. The average attitude score was 29 which reflected a positive attitude towards clients with AIDS. No correlation was found between knowledge and attitudes; previous AIDS education made no difference in knowledge scores. The knowledge questions may be outdated which could have affected the results.

Although findings of this study cannot be generalized to other populations, this research is useful because it provides data and information about the knowledge and attitudes of home care nurses towards clients with AIDS. 
ACKNOWLEDGEMENTS

I would like to thank all of my thesis committee members, participants of the study, and family members who have helped me to create and complete this thesis.

Most of all, I thank my loving husband for his support and patience during this process. 


\section{TABLE OF CONTENTS}

PAGE

LIST OF TABLES................................................................................. viii

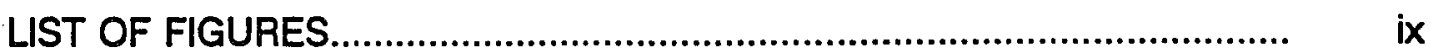

\section{Chapter}

1. INTRODUCTION...........................................................................

The Problem............................................................................... 1

Research Questions................................................................... 3

Purpose and Need.................................................................... 4

Definition of Terms......................................................................... 4

2. CONCEPTUAL FRAMEWORK AND REVIEW

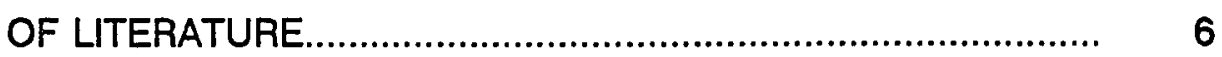

Conceptual Framework.............................................................. 6

Review of Literature.................................................................... 9

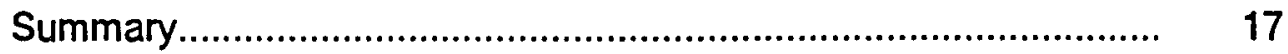

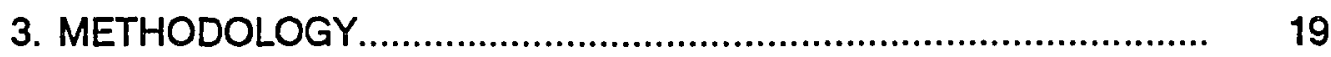

Research Design ..................................................................... 19

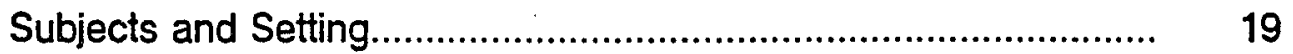

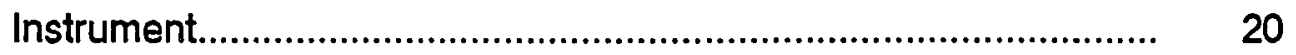

Data Collection.......................................................................... 22 
PAGE

Analysis Procedures.................................................................. 23

4. FINDINGS AND INTERPRETATION OF DATA.............................. 25

Description of the Sample............................................................. 25

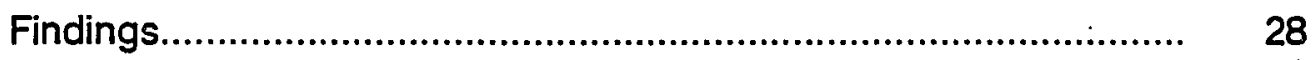

5. CONCLUSIONS AND RECOMMENDATIONS................................ 39

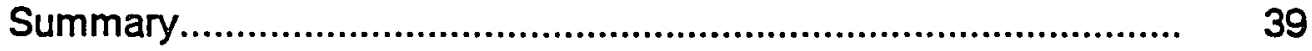

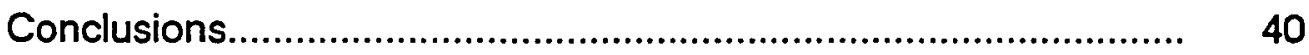

Recommendations................................................................. 41

Scope and Limitations........................................................... 42

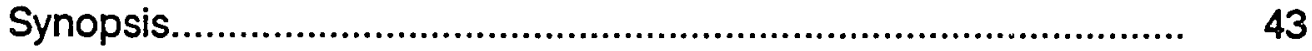

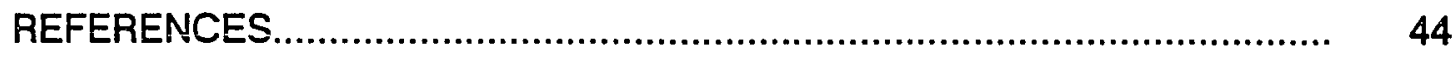

APPENDIXES

A. Permission Letter................................................................. 50

B. Approval Letter.................................................................. 52

C. Questionnaire...................................................................... 54

D. Informed Consent Cover Letter.................................................. 58 


\section{LIST OF TABLES}

PAGE

Table

1. Demographic Data of Respondents............................................... 26

2. Total Response of Attitudes......................................................... 32

3. Knowledge Scores Related to Attitudes Scores.............................. 34

4. Knowledge Scores of Nurses Who Have Had

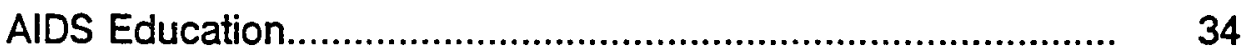

5. Knowledge Scores of Nurses Who Have Not Had

AIDS Education................................................................. 


\section{LIST OF FIGURES}

\section{PAGE}

\section{Figure}

1. Knowledge Scores of Respondents............................................... 30

2. Attitude Scores of Respondents................................................. 30 


\section{Chapter 1}

\section{INTRODUCTION}

The relationship of knowledge to the attitudes of nurses towards caring for people with acquired immunodeficiency syndrome (AIDS) has become a recent area of study. Certain negative attitudes may have an affect upon the care given to patients with AIDS (Hunter \& Ross, 1991; Dworkin, Albreight, \& Cooksey, 1991). Nurses' attitudes towards patients with AIDS have been investigated (Reed, Wise, \& Mann, 1984; Kelly, 1988), but little research has been done on how knowledge about this disease affects attitudes. This study was designed to examine the relationship between nurses' knowledge of AIDS and their attitudes towards caring for people with AIDS.

Problem

AIDS is a disease caused by the human immunodeficiency virus (HIV). The virus attacks the immune system making the individual susceptible to a variety of opportunistic infections (Goff \& McDonough, 1986). Since there is presently no known cure for AIDS, the number of people afflicted is constantly increasing. In 1993, the Public Health Service estimates that between 945,000 and 1.4 million people are infected with the AIDS virus, and approximately 135,434 people have died as a result of AIDS (Centers for Disease Control, 1992). 
People with AIDS related diseases are difficult to care for due to their complexity of problems. The body systems most frequently involved are the respiratory, gastrointestinal, integumentary, and nervous systems.

Pneumocystic pneumonia (respiratory), Kaposi's sarcoma (integumentary and gastrointestinal), and toxoplasmosis (nervous) are just a few of the opportunistic infections which increase the complexity of the nursing care needs of people with AIDS (Goff \& McDonough, 1986).

Caring for people with AIDS is a modern nursing problem because of the complexity of the disease and the problems which exist within the nursing profession itself. Fear of AIDS, lack of AIDS education, negative attitudes towards people with AIDS, and AIDS patients requiring additional staffing are all problems which lead to anxiety of nurses about caring for people with AIDS. This anxiety can lead to additional stress, both personally and professionally among those riurses involved in caring for this population (Reed, Wise, \& Mann, 1984).

Earlier disease detection, the use of antivirals and other agents that prolong life, the growing number of infected individuals, and earlier discharges from the hospital threaten to exacerbate the existing AIDS care problems both in the hospital and home settings (Gee, 1992; Schneitz, 1992). Therefore, home care nurses are becoming the primary care providers for people with AIDS (Schneitz, 1992). Because home care nurses are spending large amounts 
of time with AIDS patients, it is important to examine how their attitudes are affected because of this increased contact.

Nurses need to be aware of situations in which biases towards AIDS patients may lead to inferior nursing care. If nurses are aware of their biases, then inequities in care may be avoided (Gee, 1992). Many researchers have reported on nurses' attitudes towards patient care, but only a few have studied the possible negative attitudes of nurses towards AIDS patients, a patient population generally perceived to be responsible for acquiring their illness (Brink, 1984). The public perceives the nursing profession as being empathetic towards all patients, but in reality, nurses do not feel empathetic towards all of their patients, especially those with AIDS (Scherer, Yow-Wu, \& Haughey, 1991).

\section{Research Questions}

Four questions were addressed in this study.

1. What is the knowledge of home care nurses concerning AIDS?

2. What are the attitudes of home care nurses towards clients with AIDS?

3. Is there a relationship between knowledge of AIDS and nurses' attitude toward clients with AIDS?

4. Is there a difference in the knowledge of AIDS between nurses who had previous AIDS education and nurses who did not? 
Purpose and Need

The purpose of this study was to examine if nurses' knowledge was related to their attitudes towards clients with AIDS. This study compared (a) nurses' attitudes toward caring for AIDS clients in relationship to knowledge about AIDS, (b) the difference in the knowledge of AIDS between nurses who had previous AIDS education and nurses who did not, and (c) nurses' attitudes towards caring for AIDS clients and nurses' knowledge of AIDS in relationship to selected demographic data. Since van Servellen, Lewis, and Leake (1988) suggest that nurses' knowledge and attitudes affect the care which is given to AIDS patients, this study may assist in determining if knowledge does significantly affect nurses' attitudes and is therefore a worthy subject to research.

This study is important to patient care, in both inpatient and outpatient settings, because specific issues of quality of care are explored. Also, the profession of nursing can benefit from this information, because it can be used to make nurses aware of their attitudes so that biases in care can be avoided. therefore promoting high quality of care to people with AIDS.

Definition of Terms

The following definitions were used in this study:

1. Registered Nurse refers to a person licensed to practice as a registered nurse by a state board of registered nursing. 
2. Attitude refers to a fairly stable emotional tendency to respond consistently to some person, object, or situation (Williamson, Swingle, \& Sargent, 1986, p. 215).

3. AIDS (acquired immunodeficiency syndrome) refers to a diagnosed disease state cause by the human immunodeficiency virus (HIV). The virus attacks the immune system making the individual susceptible to a variety of opportunistic infections (Goff \& McDonough, 1986).

4. AIDS Education is information explaining and describing accurate data regarding all aspects of AIDS (Dawdle, 1983).

5. Knowledge is acquaintance with facts, truths, or principles from study or investigation (Barnhardt, 1983) regarding AIDS information.

This chapter describes the problem of AIDS and the problems in nursing when caring for people with AIDS. It shows why it is important to do research in the area of nurses' attitudes towards clients with AIDS. It outlines the research questions which were asked and the definition of terms used in this study. The next chapter will focus on the conceptual framework and the review of recent studies in the area of attitudes and AIDS. 
Chapter 2

CONCEPTUAL FRAMEWORK AND REVIEW OF LITERATURE

The conceptual framework used for the study is based on the concept of how attitudes influence behavior and how knowledge can influence attitudes. A review of literature focuses on the related studies of attitudes towards patients with AIDS and how education can change these attitudes.

\section{Conceptual Framework}

White (1977) discusses how attitudes influence behavior and how knowledge can influence attitudes. White believes that an individual's feelings and/or knowledge in a particular situation, in response to a stimulus, will cause that individual to behave in a particular way. This model was chosen because, during the review of literature. White's model was frequently referenced and was the foundation for many studies and conceptual frameworks regarding nurses' attitudes and knowledge.

The assumptions that follow are used to construct a context in which to view the nurse and patient encounter: (a) nurses interact with patients within a health care environment. (b) the quality of this environment influences the nurse and the patient, (c) the actions of the patient and nurse are influenced by the attitudes and actions of each other, and (d) attitudes should not be viewed as permanent. These assumptions are then taken into account when examining 
how knowledge can affect nurses' attitudes leading to either a positive or negative behavior when providing patient care (White, 1977).

The following concepts show the model's sequence of events from stimulus to action. This sequence of events occurs in three steps. First, a particular stimulus will evoke feelings, knowledge, and previous experience relating to the particular situation. Next, the feelings, knowledge, and previous experience will combine to form an attitude. Finally, the attitude will lead to either a positive or negative behavior depending on the individual experiencing the situation (White, 1977).

The following is an example of the nurse patient encounter using White's model. A home care nurse has to visit a patient with AIDS. In the past, this nurse has had only negative experiences when working with people with AIDS and feels inadequately educated to care for this patient. These feelings of negativity and lack of education combine to form a negative attitude toward this patient. This attitude is then reflected in the nurses' behavior toward that patient, illustrated by the nurse not fully assessing the patient or not following through with the plan of care. The patient therefore receives inferior care because of the negative attitude.

White's (1977) model has been used by many others to explain the relationship between attitudes, behavior, and knowledge, making this model credible (Blumenfield, 1987; Turner, McLaughlin, \& Shrum, 1988; Young, 1988; 
van Servellen et al., 1988; Schietinger, 1986; Neal, 1983). Blumenfield (1987) uses this model as the foundation for studying nurses' attitudes towards AIDS; the results revealed that misinformation leads to negative attitudes which are demonstrated by unneeded fear and apprehension towards people with AIDS. Neal (1983) also uses the same concepts when describing attitudes, behavior, and knowledge. He states that attitudes can be effective as predictors of behavioral trends and are formed by previous feelings and knowledge. These attitudes then form a behavioral component, which is an action or reaction to objects, situations, or events. These reactions occur because of the previously formed attitudes and can be positive or negative. Neal (1983) concludes that it is important to look at these steps which form attitudes because they affect the dynamics of social life, which in turn can affect many people. Young (1988) uses these same strategies when applying teaching methodology to changing nursing attitudes toward homosexuality. Young suggests that misinformation which leads to negative attitudes can be changed through education turning negative attitudes to neutral or positive ones. van Servellen et al. (1988) use White's scheme when studying nurses' attitudes and AIDS. They conclude that knowledge affects attitudes and attitudes affect the care which is given to AIDS patients.

White's model has been successfully used when looking at the relationship between knowledge, attitudes, and behavior. This framework will 
be used to show how knowledge about AIDS can affect nurses' attitudes and how AIDS education can affect nurses' knowledge.

\section{Review of Literature}

The following literature review focuses on attitudes and behavior, attitudes towards AIDS, and how knowledge and education can affect attitudes.

\section{Attitudes and Behavior}

White (1977) identifies that attitudes about persons, ideas, and situations are all communicated by behavior. Behavior is defined as "the way a person responds to or acts with the environment" (Witt, 1990, p. 127). An attitude is a fairly stable emotional tendency to respond consistently to some object. situation, or person (Williamson et al., 1982).

Attitudes have been discussed by a number of investigators. According to Neal (1983) and White (1977), attitudes often influence behavior and are learned from past experience, and even though they are often resistant to change, can be relearned and modified. John (1983) believes attitudes can influence behavior toward some object, situation, person, or group; and Brink (1984) notes that attitudes reflect value systems and are revealed in behaviors, expectations, and feelings. The attitudes of nurses are especially important in health care, because attitudes may have an effect upon the care given to patients (Hunter \& Ross, 1991). 
White (1977) suggests that attitudes will lead to either positive or negative behaviors, and behaviors can be exhibited by a variety of responses depending on the situation. Gee (1989) expands on this by saying that there is a relatively high degree of anxiety or discomfort, homophobia, and fear of contagion among nurses caring for AIDS patients. Such attitudes manifest behaviors of avoidance of the patient, attribution of negative characteristics to or devaluation of the homosexual patient, and refusal of care.

Brink (1984) suggests that some nurses see patients as provoking victims. She states that "just as victims of a crime are often accused of provoking the crime, ... patients are victimized at times by the moral judgments nurses make about the degree to which patients are 'responsible' for their health problems" (p. 964). This is often the judgment made towards people with AIDS.

Nurses are members of the public and are neither isolated from nor unaffected by public attitudes. Despite their education and training, nurses' perceptions on a variety of issues will be influenced both positively and negatively by their familial, cultural, and socioeconomic backgrounds (Gee, 1989). Therefore, even though nurses are health care professionals, they may have negative attitudes when caring for AIDS patients due to their various backgrounds. The ramifications of negative attitudes can lead to a lower quality 
of health care when caring for the AIDS patient population (Douglas, Kalman, \& Kalman, 1985).

\section{Attitudes and AIDS}

Hunter and Ross (1991) studied nursing students, occupational therapy students, and health care workers enrolled in a postgraduate health administration course. They found there was negativity toward particular patient groups based on patient lifestyles and suggested that the negative attitudes toward people with AIDS may be a reflection of negative attitudes towards sexuality in general, rather than homosexuality.

The investigation by Scherer, Wu, and Haughey (1991) of AIDS and homophobia among registered nurses revealed negative attitudes and stereotypes. Two significant findings were noted: (a) some nurses had become more negative towards homosexuality since the AIDS crisis began; and (b) some were more sympathetic toward individuals who acquired AIDS from transfusions rather than from homosexual practices. This suggests their negative attitudes towards AIDS may be due to an unconscious homophobia. The authors state that it is crucial to uncover and help nurses deal with negative attitudes toward this patient population because of the impact on quality of care to patients with AIDS.

Reed, Wise, and Mann (1984) surveyed the attitudes of nurses regarding. the care of AIDS patients and suggested possible anxiety. They found that 
negative attitudes were reported when caring for AIDS patients even though the respondent had acquired a reasonable understanding of AIDS. They documented that the foremost reasons for negative attitudes were fear of contagion and homophobia.

Studies conducted by Brennan (1989) and by van Servellen. Lewis, and Leake (1988) surveyed nurses' attitudes towards AIDS. Both studies concluded that concerns over contagion and adequacy of infection control precautions persisted. Therefore, nurses' fears and negative attitudes also persisted, with nurses expressing discomfort with or even dislike for giving care to individuals with AIDS.

Kelly (1988) studied nurses to determine attitudes towards AIDS and patients with gay lifestyles. Study results indicated that nurses had more negative attitudes toward the patient labeled as having AIDS than toward the identically described patient with leukemia. These attitudes included feelings that the individuals with AIDS were responsible for what had happened to them, they were deserving of what had happened to them, they were dangerous to others, their deaths were of less importance, and they were deserving of quarantine. The nurses responded to the homosexual patient and AIDS patient with nearly identical negative attitudes.

Royse and Birge (1987) examined homophobia and attitudes toward AIDS patients among nursing students. They concluded through a survey that 
greater homophobia in individual students was associated with less empathy for AIDS patients and greater fear of the disease.

As cited above, many factors contribute to negative attitudes towards patients with AIDS. AIDS education is a complex area in which to inform nurses because of the many factors which contribute to the formation of attitudes.

\section{Knowledge, Education, and Attitudes}

Education is defined as the process of training and developing the knowledge, skill, mind, or character by formal teaching or training (Witt, 1990). For nurses' attitudes to improve, their perspective of AIDS has to change, and this can be accomplished through AIDS education (AIDS Update, 1992). White (1977) states that while feelings, knowledge, and previous experience combine to form an attitude, feelings and previous experience cannot be altered, but knowledge level can be changed and knowledge can be gained by obtaining skills through special education programs.

Freedman, Carlsmith, and Sears (1981) suggest that to develop an attitude, an individual acquires information and feelings by the process of reinforcement, imitation, and association. Associations occur when stimuli appear at the same time and place. For example, if a person sees an object or person and hears an adjective to describe it, they may associate the person or object with the adjective if they encounter it later. Reinforcement also forms attitudes: If a person has a number of positive associations, then he/she will 
probably form a positive attitude. Attitudes are also learned through role modeling. People imitate the behavior of others, especially if the role models are strong and important people. For example, if both management and staff have a positive attitude toward a particular situation, then a newly hired employee will be more likely to assume a similar attitude.

Other teaching methodologies may be used to change attitudes. Turner et al. (1988) suggest that through seminars, which include a structured session on attitude resolution, both knowledge levels and attitudes will improve with education. Young (1988) found that attitudes and feelings can be neutralized by discussion in a non-threatening environment.

Lack of education is perhaps the major reason why nurses do not want to care for patients with AIDS. Fear of contagion, bringing it home to their children, and homophobia are frequent reasons given for not wanting to provide care (Goff \& McDonough, 1986; Schietinger, 1986; Royse \& Birge, 1987; Kelly, 1988; Brennan, 1988; van Servellen et al., 1988). Goff and McDonough (1986) note that though nurses usually do not refuse to care for this patient population, the fears mentioned above lead to negative attitudes when caring for patients with AIDS. The challenge in caring for AIDS patients can be exhausting as well as rewarding. A well planned approach to caring for AIDS patients will help the nurse deal with the complex issue of AIDS care and hopefully decrease anxieties. Educational programs are an excellent solution to alleviate 
unwarranted concerns and fears. Nurses also need to have ongoing inservice programs and support services to help decrease anxieties.

Schietinger (1986) suggests that social rejection because of fear of contagion occurs not only by friends, family, and the general public, but also by uninformed health care workers. Lack of information promotes fear, impairing the ability of the nurse to provide good care. Continuing education and inservice programs are critical factors in determining whether the attitudes of nurses are negative or positive towards AIDS patients.

Harnett (1987) found many unforeseen problems related to caring for AIDS patients; these problems exposed the gaps in hospital staff knowledge and practices. Her proposal of education to promote understanding is an important component of nursing intervention towards people with AIDS. Information can calm fears and increase confidence about caring for patients with AIDS. As nurses gain increased knowledge and experience with AIDS patients, and if these experiences are considered positive, then their attitudes should change, becoming more positive.

The following studies indicate that education is an important factor to changing attitudes towards patients with AIDS. This is important, because education leads to greater knowledge which can, in turn, affect attitudes.

Wertz (1989) used a pretest and posttest to assess the impact of education on nurses' knowledge and attitudes about AIDS. Following classes, 
attitudes about AIDS patients shifted in a more positive direction, with respondents expressing increased confidence in their ability to protect themselves, provide complete care, and interact with the lovers of AIDS patients. Wertz concluded that education proved effective in improving knowledge and attitudes.

Brennan (1988) surveyed nurses' attitudes about AIDS and asked what would be most helpful to nurses working with AIDS patients. The result was that nurses felt that educational information was the key to calming fears and changing negative attitudes.

Barrick (1988) surveyed nurses to determine if there was a correlation between nurses' attitudes about homosexuality and their willingness to care for an AIDS patient. The study revealed that a positive attitude toward gay men and lesbians correlated positively with the willingness to care for AIDS patients. Barrick noted that programs designed to normalize nurses' reactions with homosexual patients are key to increasing the nurses' willingness to 'care for people with AIDS, and that nurse managers and educators need to be sensitive to anti-sexual bias as it is manifested in nursing care.

Turner (1988) compared a control group of nurses to an experimental group. The experimental group was enrolled in an AIDS seminar that included a structured session on attitude resolution relative to caring for AIDS patients. Pretest and posttest results demonstrated that general AIDS knowledge among 
nurses was high to begin with, but both knowledge levels and attitudes improved with education. In addition, the posttest revealed that subjects who exhibited increased knowledge demonstrated more positive attitudes towards AIDS related issues.

Young (1988) used an open forum with nurses to discuss feelings and attitudes about AIDS and homosexuals. Pretest and posttest surveys were done to assess changes in attitudes. Posttests revealed that those who responded negatively about AIDS and homosexuality at the beginning of the forum expressed neutral feelings about them at the end of the session.

Turner, McLaughlin, and Shrum (1988) used a similar model of education in which fear, anger, and negative attitudes about AIDS were discussed openly among nurses. They also found that after the discussion, nurses' feelings were more neutral towards AIDS patients.

\section{Summary}

This literature review supports the contention that attitudes affect behavior, that education develops knowledge, and that knowledge affects attitudes (White, 1977; Neal, 1983; Douglas et al., 1985; Freedman et al., 1981; Goff \& MCDonough, 1986). Studies also demonstrate that negative attitudes towards AIDS patients do exist among nurses leading to avoidance of the patient, devaluation of the homosexual patient, and refusal of care (Gee, 1989; · Scherer et al., 1991; Kelly, 1988; Barrick, 1988). Many studies documented that 
AIDS education can have a positive effect towards changing attitudes of nurses (Wertz, 1989; Harnett, 1987; Brennan, 1988; Turner et al., 1988; Young, 1988). 


\section{Chapter 3}

\section{METHODOLOGY}

This chapter describes the research design, subjects and setting, human subjects approval, instrument, data collection, and analysis procedures of the data for this research.

\section{Research Design}

The purpose of this study was to examine whether nurses' knowledge of AIDS was related to their attitudes towards people with AIDS. The study design was descriptive using correlation statistics. The aim of this study was to describe the relationships among variables rather than infer cause and effect relationships (Wilson, 1989).

\section{Subjects and Setting}

The setting for this study was a home care agency located on the central coast of California. The agency services an area consisting of approximately 200,000 people. All nurses employed by this agency were asked to participate in this study. These subjects were chosen because a large percentage of their clientele have AIDS or HIV related conditions.

The population was a convenience sample consisting of the 34 registered nurses who were employed by this agency. The subjects were 
informed that their participation in the study was strictly voluntary and the questionnaires would remain completely anonymous and confidential.

Prior to implementing the research, approval was obtained from the home care agency director of nursing (Appendix A) and the Committee for the Protection of Human Subjects at San Jose State University (Appendix B). Questionnaires were distributed to the respondents over a period of 2 days. Instrument

A questionnaire developed by Mcllvenna (1988) was used for this study (Appendix C). She states that "validity issues and limitations exist with the instrument due to its newness and previously untested material contained in the questionnaire" (Mcllvenna, 1988, p. 20). The instrument has been used only once prior to this study. It was used because it was the only one the researcher could find which specifically addresses nurses' attitudes towards clients with AIDS. The questionnaire was divided into three parts. The first section collected demographic data, the second section ascertained the subjects' knowledge of AIDS, and the third section examined the subjects' attitudes towards people with AIDS.

Section one requested demographic information which included: (a) age. (b) marital status, (c) family status, (d) religion, (e) education level, (f) nursing title, (g) nursing years of experience, $(\mathrm{h})$ completion of an AIDS education program, (i) type and frequency of contact with AIDS patients during work, and 
(j) type and frequency of contact with AIDS patients at home. Section two measured the subjects' knowledge of AIDS and included true and false questions regarding factual information about AIDS. This section asked questions in the following areas: (a) definition of AIDS, (b) signs and symptoms of AIDS, (c) care of people with AIDS, (d) epidemiology of AIDS, and (e) infection control of AIDS. Correctly answered questions received a score of one, and incorrectly answered questions received a score of zero. A total score of 10 was possible.

Section three measured the subjects' attitudes towards people with AIDS. This section consisted of seven statements which asked the respondents to indicate their level of agreement or disagreement with each statement. The statements were worded both negatively and positively regarding the attitudes of nurses towards people with AIDS. Responses to the seven statements were based on a 5-point Likert scale which used the following definitions: 1-strongly disagree, 2-disagree, 3-uncertain, 4-agree, 5-strongly agree.

The Likert scale method required the respondents to indicate their level of agreement or disagreement with each statement, with strong agreement receiving the highest scores and strong disagreement receiving the lowest scores. All statements except one (question 26) were worded in a positive manner; this score was adjusted for in the analysis. Each statement response ranged from one to five. The minimum score obtainable was 7 and represented 
a negative attitude. The maximum score was 35 and represented a positive attitude. A neutral attitude would be represented by a score of 17 .

Data Collection

Prior to the start of the survey, a meeting was arranged with the agency's director of nursing to discuss the following: (a) explain the nature and purpose of the study, (b) determine the best method of distributing the questionnaire so the maximum number of nurses could be reached, (c) coordinate a time frame in which to explain the study and collect the data with minimal disruption. It was agreed that the most appropriate time to distribute the questionnaires would be at a weekly mandatory staff meeting so that a maximum number of nurses could be reached with minimal disruption.

On the designated day, the investigator attended the mandatory staff meeting and gave a brief inservice about the study including the following:

1. Nature, purpose, and benefits of the study.

2. Procedure for completing and returning the instruments.

3. Location of the collection box.

4. Time frame in conducting the study.

5. Confidentiality of responses and voluntary participation.

The nurses were encouraged to ask questions about the study. They were informed that participation was strictly voluntary, and confidentiality was stressed; choosing not to participate in the study would not affect their 
employment status with the agency or any relations with San Jose State University.

All nurses present were given a packet consisting of a cover letter, which also acted as a consent form (Appendix D), and the three part questionnaire. After reading the cover ietter, the subjects could then decide whether or not to participate in the study. If they filled out the questionnaire, this was considered to be giving consent to participate. The subjects were encouraged to complete the questionnaire within 7 days and to deposit it in the investigator's mail box. After a week, the investigator left a follow-up message on the nurses' voice mail system encouraging completion and return of the questionnaires as soon as possible. Fourteen days after the questionnaires were distributed, they were collected and prepared for data analysis. A total of 34 questionnaires were distributed, with a return of 32 , a response rate of $94 \%$. All the data collected were stored in a secure location.

\section{Analysis Procedures}

The data were analyzed by a statistician using the Statistical Package for the Social Sciences (SPSS). SPSS is one of the most widely-used software packages because it is widely available and fairly easy to learn and use Wilson. 1989).

The data obtained in this study were responses to a three part questionnaire, in which the subjects were asked to circle their responses to 
demographic information, AIDS knowledge, and attitudes towards people with AIDS. Demographic information was tallied, using a frequency table to construct a demographic profile of the 32 respondents. To assess knowledge level, a possible maximum score of 10 was given, with percentage correct determining level of knowledge. Knowledge of AIDS in relationship to attitudes was correlated using a Pearson r correlation coefficient. To assess attitudes towards people with AIDS, a range of scores from a minimum of 7 to a maximum of 35 was given to determine if attitudes were negative or positive. An independent t-test was used to determine if there was a difference in knowledge of AIDS between those nurses who had previous education and those who did not.

The purpose of the data analysis was to answer the research questions stated in Chapter 1. Chapter 4 will show the results of the data analysis and discuss the findings and interpretations of the study. 


\section{Chapter 4}

\section{FINDINGS AND INTERPRETATION OF THE DATA}

This chapter describes the findings from this study which examined the attitudes of 32 home care nurses toward clients with AIDS. The data were analyzed to determine if there was a relationship between attitudes and a knowledge of AIDS, and if there was a difference in knowledge of AIDS between those nurses who had AIDS education and those who did not.

\section{Description of the Sample}

Thirty-four questionnaires were distributed, and 32 were returned, a response rate of $94 \%$. Demographic data indicated that two age groups made up the majority of the sample: $30-39(31.5 \%)$ and $50-59(31.5 \%)$. Most of the respondents were married (38\%) and had children $(63 \%)$. Twenty-two (69\%) had some kind of religious belief with the majority $(31 \%)$ indicating a Protestant religion. Fifteen (47\%) of the respondents had 16 years of education, and all of the respondents were registered nurses. Twenty-one (66\%) had more than 10 years nursing experience, and $20(63 \%)$ had completed an AIDS education program. Twenty-five $(78 \%)$ of the nurses worked with more than five patients with AIDS a year. Ten (31\%) responded they were unaware of any contact with people with AIDS outside the work setting. Table 1 displays the demographic data of the respondents. 
Table 1

Demographic Data of Respondents $(\mathrm{N}=32)$.

\begin{tabular}{|c|c|c|}
\hline Descriptors & Response Frequency & Response Percentage \\
\hline \multicolumn{3}{|l|}{ Age } \\
\hline $21-29$ & 3 & $9.0 \%$ \\
\hline $30-39$ & 10 & $31.5 \%$ \\
\hline $40-49$ & 8 & $25.0 \%$ \\
\hline $50-59$ & 10 & $31.5 \%$ \\
\hline $60-69$ & 1 & $3.0 \%$ \\
\hline \multicolumn{3}{|l|}{ Marital Status } \\
\hline Single & 6 & $19.0 \%$ \\
\hline Married & 12 & $38.0 \%$ \\
\hline Separated & 1 & $3.0 \%$ \\
\hline Divorced & 8 & $25.0 \%$ \\
\hline Widowed & 2 & $6.0 \%$ \\
\hline Living $w /$ significant & 3 & $9.0 \%$ \\
\hline \multicolumn{3}{|l|}{ Family Status } \\
\hline No children & 12 & $37.0 \%$ \\
\hline Have children & 20 & $63.0 \%$ \\
\hline \multicolumn{3}{|l|}{ Religious Beliefs } \\
\hline Yes & 22 & $69.0 \%$ \\
\hline No & 8 & $25.0 \%$ \\
\hline No Response & 2 & $6.0 \%$ \\
\hline \multicolumn{3}{|l|}{ Name of Religion } \\
\hline None & 9 & $28.0 \%$ \\
\hline Protestant & 10 & $31.0 \%$ \\
\hline Catholic & 4 & $13.0 \%$ \\
\hline Jewish & 3 & $9.0 \%$ \\
\hline Religious Science & 2 & $6.0 \%$ \\
\hline No Response & 4 & $13.0 \%$ \\
\hline
\end{tabular}


Table 1 (continued)

\begin{tabular}{|c|c|c|}
\hline Descriptors & Response Frequency & Response Percentage \\
\hline \multicolumn{3}{|l|}{ Highest Grade Level Completed } \\
\hline 14 & 6 & $19.0 \%$ \\
\hline 15 & 3 & $9.0 \%$ \\
\hline 16 & 15 & $47.0 \%$ \\
\hline 17 & 1 & $3.0 \%$ \\
\hline 18 & 4 & $13.0 \%$ \\
\hline 20 & 2 & $6.0 \%$ \\
\hline No Response & 1 & $3.0 \%$ \\
\hline \multicolumn{3}{|l|}{ Nursing Title } \\
\hline RN & 32 & $100.0 \%$ \\
\hline \multicolumn{3}{|l|}{ Years in Nursing } \\
\hline Less than 10 years & 11 & $34.0 \%$ \\
\hline More than 10 years & 21 & $66.0 \%$ \\
\hline \multicolumn{3}{|l|}{$\begin{array}{l}\text { Completion of AIDS } \\
\text { Education Program }\end{array}$} \\
\hline Yes & 20 & $63.0 \%$ \\
\hline No & 12 & $37.0 \%$ \\
\hline \multicolumn{3}{|l|}{ Contact with AIDS Patients } \\
\hline Less than 5 patients per year & 7 & $22.0 \%$ \\
\hline More than 5 patients per year & 25 & $78.0 \%$ \\
\hline \multicolumn{3}{|l|}{$\begin{array}{l}\text { Contact with Friends or } \\
\text { Family with AIDS }\end{array}$} \\
\hline No contact & 7 & $22.0 \%$ \\
\hline Unknown contact & 10 & $31.0 \%$ \\
\hline Less than 5 patients per year & 7 & $22.0 \%$ \\
\hline More than 5 patients per year & 8 & $25.0 \%$ \\
\hline
\end{tabular}




\section{Findings}

Research Question \#1. What is the knowledge base of home care nurses concerning AIDS?

Section two of the questionnaire measured the subjects' knowledge of AIDS. This section included 10 true and false questions regarding factual information about AIDS. Each question was valued as 1 point, and the knowledge scores were determined by how many questions were answered correctly. The highest score obtainable was 10 points.

The data from this study indicated that all 32 of the respondents scored $80 \%$ or better on the knowledge test about AIDS. Fifteen ( $47 \%$ ) had a score of $10(100 \%), 13(40 \%)$ had a score of $9(90 \%)$, and $4(13 \%)$ had a score of 8 $(80 \%)$. Figure 1 displays the total knowledge scores.

Research Question \#2. What are the attitudes of home care nurses towards clients with AIDS?

Section three of the questionnaire measured the subjects' attitudes towards clients with AIDS. The attitudes were assessed by answering seven statements (items 22 through 28). The subjects responded using a Likert scale ranging from 1 (strongly disagree) to 5 (strongly agree). When scoring each individual statement, a positive attitude or response was in the range of 4 or 5 , a neutral attitude was 3 , and a negative attitude was a 1 or 2 . The minimum score obtainable was 7 ; a score from 7 to 11 would represent a negative 
attitude. A neutral attitude was represented by a score of 12 to 23 , and a positive attitude was represented by a score of 24 to 35 .

One (3\%) respondent had an attitude score of 20 . The highest score was 35, with $2(6 \%)$ respondents in this area. The average score was 29 which reflects a generally positive attitude towards clients with AIDS. Figure 2 shows the scores and response rates.

The findings indicate that $14(43 \%)$ of the respondents had positive attitudes for question 22, "I feel caring for AIDS patients should be voluntary," $6(19 \%)$ were uncertain about their feelings, and $12(38 \%)$ agreed that caring for people with AIDS should be voluntary, displaying a negative attiłude. Question 23, "I would feel comfortable sitting next to or talking to an AIDS patient," indicated positive attitudes, with all $32(100 \%)$ nurses scoring positively; four (12\%) agreed, and 28 (88\%) respondents strongly agreed: Question 24 states, "I would take particular care to make a patient with AIDS comfortable," the response to this statement was mostly positive, with 30 (94\%) nurses responding positively. One (3\%) was uncertain, and one $(3 \%)$ responded negatively. Question 25, "I would feel comfortable in performing CPR on a patient with AIDS," was the question with the most diverse responses. Eleven (34\%) responded positively that they would feel comfortable; 13 (41\%) were uncertain, and $8(25 \%)$ responded negatively that they would not feel comfortable. Question 26 which states, "I am morally offended by people with 
Figure 1

Knowledge Scores of Respondents ( $\mathrm{N}=32$ )
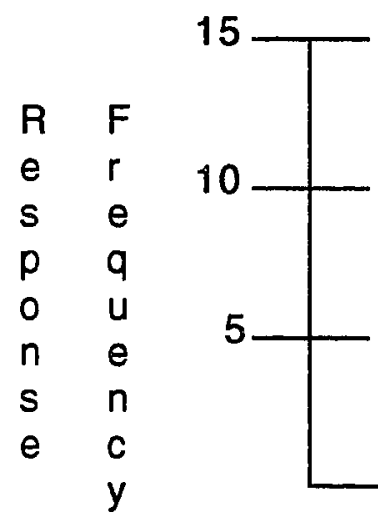

Figure 2

\section{Attitude Scores of Respondents ( $\mathrm{N}=32$ )}

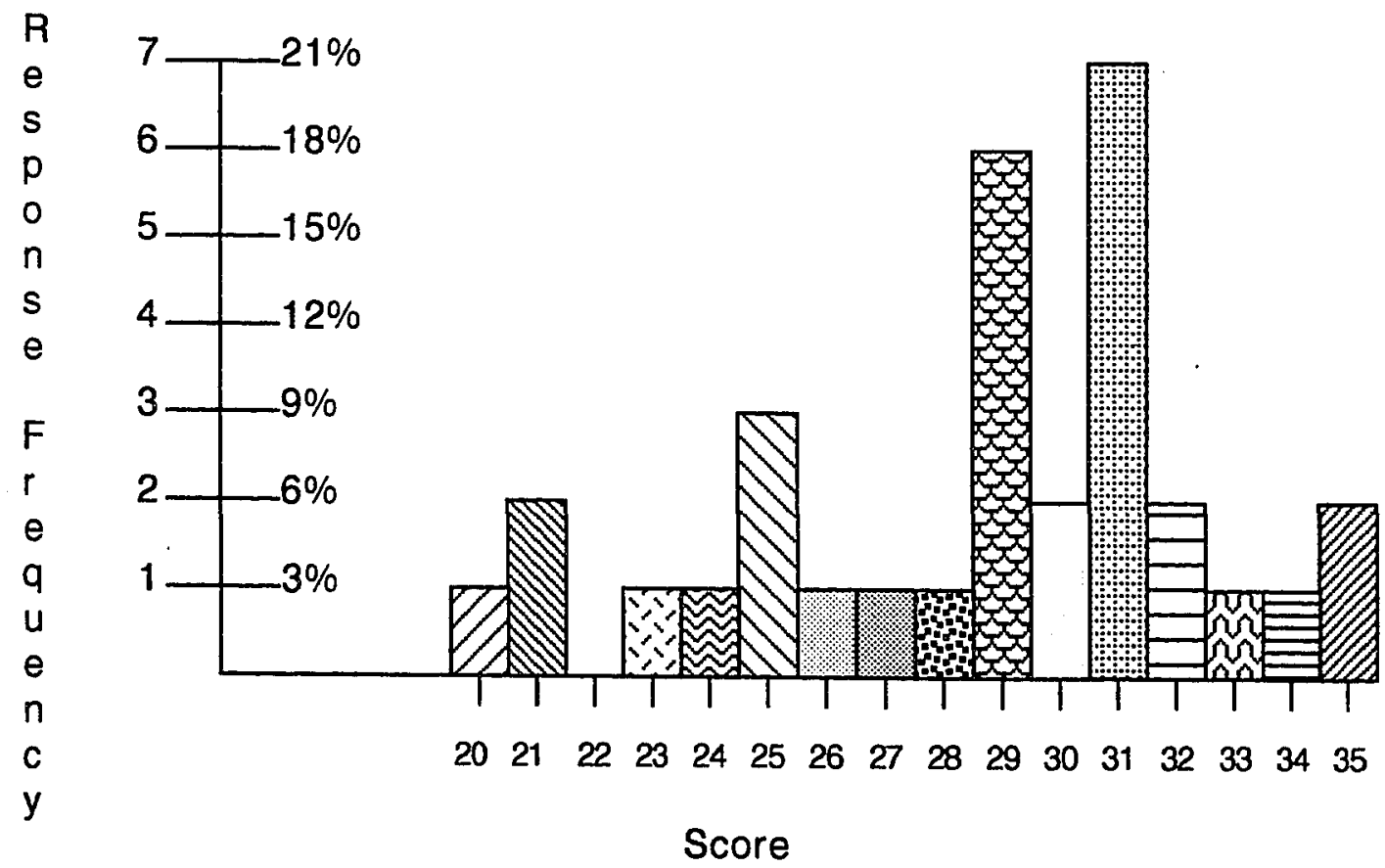


AIDS" is the only statement written in a negative form; therefore, the responses of agree (negative response) and disagree (positive response) are reversed in this situation. Twenty-nine (91\%) of the respondents had a positive response and disagreed with this statement, one (3\%) respondent strongly agreed with this statement, and $2(6 \%)$ were uncertain of their feelings. Question 27, "I would feel comfortable caring for an AIDS patient in the course of my work day," received 28 (88\%) positive responses, one (3\%) negative response, and three (9\%) uncertain responses. "I would feel comfortable having my relative room with an AIDS patient," question 28, received 20 (63\%) positive responses. two (6\%) negative responses, and $10(31 \%)$ neutral or uncertain responses. Table 2 shows the statements and response rates.

Research question \#3. Is there a relationship between knowledge of AIDS and nurses' attitudes towards clients with AIDS?

Fifteen (47\%) of the respondents scored $100 \%$ on the knowledge assessment, with a mean attitude score of 30 points (87\%) representing a positive attitude. Thirteen (40\%) of the respondents scored $90 \%$ on the knowledge assessment, with a mean attitude score of 29 points (83\%), also representing a positive attitude. Four (13\%) of the respondents scored $80 \%$ on the knowledge assessment, with a mean attitude score of $24(75 \%)$ points. The latter was the lowest scoring group, but the score still indicates an overall 
Table 2

Total Response of Attitudes $(\mathrm{N}=32)$.

\section{Statement}

22. I feel caring for AIDS

Patients should be voluntary.

23. I would feel comfortable next to or talking to an AIDS patient.

24. I would take particular care to make a patient with AIDS comfortable.

25. I would feel comfortable in performing CPR on a patient with AIDS.

26. I am morally offended by people with AIDS.

27. I would feel comfortable caring for an AIDS patient in the course of my work day.

28. I would feel comfortable with an AIDS patient.

\section{having my relative room}

Responses

Negative Neutral Positive
$12(38 \%)$
$6(19 \%)$
$14(43 \%)$
$1(3 \%)$
$1(3 \%)$
$30(94 \%)$

$8(25 \%) \quad 13(41 \%) \quad 11(34 \%)$

$1(3 \%) \quad 2(6 \%) \quad 29(91 \%)$

$1(3 \%) \quad 3(9 \%) \quad 28(88 \%)$ 
positive attitude. Table 3 outlines the knowledge scores, response frequency, and attitude scores.

A Pearson r correlation coefficient was done on the total knowledge and attitude scores to determine if there was a relationship between knowledge and attitude at a selected $\mathrm{p}<.05$. The data indicated no significant correlation between knowledge and attitudes, $r=.20, p=.45$.

Research question \#4. Is there a difference in the knowledge of AIDS between nurses who had previous AIDS education and nurses who did not?

Table 4 shows the breakdown of the knowledge scores of each true-false question for the nurses who have had AIDS education, and Table 5 shows the breakdown of knowledge scores of each true-false question for the nurses who have not had AIDS education. Twenty of the nurses surveyed had AIDS education, while 12 did not.

Items answered correctly by all nurses regardless of education about AIDS included: (a) question 12, "Acquired immunodeficiency syndrome is commonly referred to as AIDS," (b) question 16, "One opportunistic infection of AIDS is pneumocystic pneumonia," and (c) question 19, "Heterosexual women can get AIDS." Eighteen (90\%) of the nurses who had AIDS education answered both item 13, "Human immunodeficiency virus (HIV) is the virus that causes AIDS," and item 14, "San Francisco, Los Angeles, Miami, and New York 
Table 3

Knowledge Scores Related to Attitude Scores $(N=32)$.

Knowledge Scores

$10(100 \%)$

$9(90 \%)$

$8(80 \%)$
Response Frequency

15

13

4
Attitude Scores

$30(87 \%)$

$29(83 \%)$

$24(75 \%)$

\section{Table 4}

Knowledge Scores of Nurses Who Have Had AIDS Education $(\mathrm{N}=20)$.

Question

Answers

True

$20(100 \%)$

True

$18(90 \%)$

14. San Francisco, Los Angeles, Miami, and New York are cities reported to have the highest incidence of AIDS cases reported.

True

$18(90 \%)$

15. AIDS patients may not be roomed together.

False

19 (95\%)

16. One opportunistic infection of AIDS is pneumocystic pneumonia.

True

$20(100 \%)$ 
Table 4 (continued)

Question

Answers

Correct Response

17. The use of condoms is an effective barrier against the spread of AIDS.

True

$19(95 \%)$

18. When a surface is contaminated with blood, it should be cleaned thoroughly with bleach.

True

$19(95 \%)$

19. Heterosexual women can get AIDS

True

$20(100 \%)$

20. The spread of AIDS can be prevented by good handwashing before and after patient care and by wearing gloves when in contact with blood.

True

$17(85 \%)$

21. Needles should not be recapped when being disposed of.

True

$17(85 \%)$

Table 5

Knowledge Scores of Nurses Who Have Not Had AIDS Education $(N=12)$.

Question

Answers

Correct Responses

12. Acquired immunodeficiency is commonly referred to as AIDS.

True

$12(100 \%)$

13. Human immunodeficiency virus (HIV) is the virus that causes AIDS.

True

$12(100 \%)$ 
Table 5 (continued)

Question

Answers

Correct Responses

14. San Francisco, Los Angeles, Miami, and New York are cities reported to have the highest incidence of AIDS cases reported.

True

$12(100 \%)$

15. AIDS patients may not be roomed together.

False

$6(55 \%)$

16. One opportunistic infection of AIDS is pneumocystic pneumonia.

True

$12(100 \%)$

17. The use of condoms is an effective barrier against the spread of AIDS.

True

$10(83 \%)$

18. When a surface is contaminated with blood, it should be cleaned thoroughly with bleach.

True

$10(83 \%)$

19. Heterosexual women can get AIDS. True

$12(100 \%)$

20. The spread of AIDS can be prevented by good handwashing before and after patient care and by wearing gloves when in contact with blood.

True

$11(92 \%)$

21. Needles should not be recapped when being disposed of.

True

$12(100 \%)$ 
cities reported to have the highest incidence of AIDS cases reported," correctly, while all of the nurses who had not had AIDS education answered them correctly. Item 15, which states "AIDS patients may not be roomed together," received $19(95 \%)$ correct responses from nurses with AIDS education, but the nurses without AIDS education scored $55 \%$ correct, with only six out of 11 answering the item correctly. One respondent without AIDS education did not answer this item. Item 17, "The use of condoms is an effective barrier against the spread of AIDS," and item 18, "When a surface is contaminated with blood it should be cleaned thoroughly with bleach," had 19 (95\%) correct responses from the nurses with AIDS education. The nurses without AIDS education had a correct response rate of $10(83 \%)$. Item 20 , which states "The spread of AIDS can be prevented by good handwashing before and after patient care and by wearing gloves when in contact with blood," had $17(85 \%)$ correct answers from the nurses who had AIDS education and $11(92 \%)$ correct responses from the nurses without AIDS education. Item 21, which states "Needles should not be recapped when being disposed of," received 17 (85\%) correct responses from nurses with AIDS education, and 12 (100\%) correct responses from nurses who had not had AIDS education. Overall, the nurses with education had an average score of $94 \%$ correct, and the nurses without education had an average score of $92 \%$ correct. 
An independent t-test was done on the knowledge score of each group to determine if there was a difference in the knowiedge of AIDS between those nurses with AIDS education and those without AIDS education. The result of $\underline{t}(30)=1.095, \underline{p}=.375$ indicates no significant difference in the knowledge of AIDS between those nurses with AIDS education and those without AIDS education.

Chapter 5 will discuss the summary of the study. It will also include the conclusions, scope, limitations, and recommendations for the study. 


\section{Chapter 5}

\section{CONCLUSIONS AND RECOMMENDATIONS}

This chapter describes the conclusions derived from the data on the attitudes of 32 nurses toward clients with AIDS. Recommendations, the scope, and limitations of this study are also included.

\section{Summary}

This study was a descriptive design which surveyed nurses employed at a home care agency located on the central coast of California. The agency services an area consisting of approximately 200,000 people. The population was a sample consisting of 32 registered nurses who were employed by this agency.

The nurses were asked to complete a three part questionnaire. The first section collected demographic data; the second section ascertained the subjects' knowledge of AIDS; and the third section examined the subjects' attitudes towards people with AIDS.

A brief inservice which explained the study was conducted at a scheduled staff meeting. Questionnaires were distributed at this meeting; the nurses were encouraged to complete and return them within 7 days. They were informed that participation was strictly voluntary, and anonymity was guaranteed. 
Thirty-four questionnaires were distributed, and 32 were returned, for a response rate of $94 \%$. Of the 32 respondents, 20 had completed an AIDS education program, and 12 had not.

\section{Conclusions}

The data from this study indicated that all 32 respondents had a better than average (80\%) score on the AIDS knowledge assessment regardless of their AIDS education. The average score of the attitude section was 29 which reflects a generally positive attitude towards clients with AIDS. These very small range of scores in both knowledge and attitude may have suppressed the degree of their relationship. A Pearson $r$ correlation coefficient was done on the total knowledge and attitude scores and indicated no significant correlation between knowledge and attitudes. An independent t-test was done on the knowledge score of each group to determine if there was a difference in the knowledge of AIDS and indicated no significant difference between those nurses with AIDS education and those without AIDS education.

When compared to the previous 1988 researcher's (Mcllvenna, 1988), findings, some differences were noted. The results from this 1993 study may be due to better public education about AIDS, different educational levels of nurses in the study, or different geographical location and setting. There has been more public education about AIDS since the original study in 1988. This availability of education may have affected the knowledge scores and attitude 
scores, making them higher and more positive in this study. Mcllvenna (1988) found that nurses who had AIDS education had a large amount of knowledge regarding AIDS, with an average score of $90 \%$. The nurses without AIDS education had a fair amount of knowledge, with an average score of $70 \%$. Mcllvenna (1988) also reported that nurses who had AIDS education indicated a more positive attitude towards people with AIDS than nurses who did not have AIDS education. This study found that all nurses scored $80 \%$ or higher on the knowledge test regardless of their education, and that all the nurses had a positive attitude regardless of their education. The previous researcher's results may differ because the respondents were not all registered nurses; some were licensed vocational nurses, and others were nurses' aides with less than a high school education (Mcllvenna, 1988). This difference in education may have made the difference when comparing AIDS education and attitudes. Also, Mcllvenna's (1988) study was conducted in an acute care hospital in central, northern California, while this study was done at a home care agency on the central coast of California.

\section{Recommendations}

Data from this study indicated that knowledge and education have no significant relationships with the attitudes of 32 home care nurses toward clients with AIDS. Since these factors have no relationship to attitudes, other variables. may need further investigation, such as homophobia and attitudes towards 
AIDS (Scherer et al., 1991; Kelly, 1988; Royce \& Birge, 1987; Young, 1988) and anxiety when caring for the AIDS patient (Reed et al., 1984).

It is recommended that this study be replicated in other geographical locations, using different settings, and using larger samples to see if knowledge and education are related to attitudes towards people with AIDS. If replicated, it is recommended that the same questionnaire be administered to registered nurses in another geographic location; this would determine if geographic locations have an effect on nurses' attitudes.

All the nurses scored $80 \%$ or better in the knowledge section; therefore, it is recommended that the tool (questionnaire) be looked at more closely and possibly modified. The information in this knowledge test may have been new when the tool was originated in 1988, but in 1993, this knowledge is well publicized and may have affected the study's results. It is possible that most of the general public would be able to answer these questions.

Finally, it is recommended that nurses' attitudes towards clients with AIDS be measured in conjunction with observation and documentation of their behavior toward these clients in other clinical settings to determine if nurses' attitudes affect patient care outside of the home setting.

Scope and Limitations

Due to the small sample size and the specific geographic location, the results of this study cannot be generalized to all nurses, even in the home 
setting. The tool has only been used once previously, and validity and reliability have not been established. Answers in the section on attitudes may have been biased because the data were gathered at the facility where the investigator and respondents were all employed; therefore, the raspondents may not have felt total anonymity which may have biased their answers.

\section{Synopsis}

Since there is presently no known cure for AIDS, the number of people afflicted is constantly increasing, making it a major epidemic throughout the world and leaving no one immune to this disease. People with AIDS have many physical and psychological needs. In order for these needs to be met in the health care setting, nurses need to be aware of their attitudes towards people with AIDS and need to stay current on the knowledge and research. Positive attitudes and updated knowledge will result in providing better care for this client population. As stated in the literature review, negative attitudes may affect how a person is perceived and cared for, making the relationship between attitudes and AIDS a subject which needs to be explored further. 


\section{REFERENCES}




\section{References}

AIDS Update. (1992). Adjustment in attitudes needed. Nursing, 22(4), 21.

Barrick, B. (1988). The willingness of nursing personnel to care for patients with acquired immunodeficiency syndrome: A survey study and recommendations. Journal of Professional Nursing, 4, 366-372.

Blumenfield, M. (1987). Survey of attitudes of nurses working with AIDS patients. General Hospital Psychiatry, 99, 58-63.

Brennan, L. (1988). The battle against AIDS: A report from the nursing front. Nursing, 18, 60-64.

Brink, P. (1984). The patient as a victim. American Journal of Nursing, 84, 964.

Center for Disease Control. (1992). Recommendations on prevention of the human immunodeficiency virus. Morbidity and Mortality Weekly Report, 40 . 8.

Dawdle. W. (1983). The epidemiology of AIDS. Public Health Reports, 98, (4), 308-312.

Douglas, C., Kalman, C., \& Kalman, T. (1985). Homophobia among physicians and nurses: An empirical study. Hospital and Community Psychiatry, 36 , 1309-1330.

Dworkin, J., Albreight, G., \& Cooksey, J. (1991). Concern about AIDS among hospital physicians, nurses, and social workers. Social Science and Medicine, 33, 239-240. 
Freedman, J., Carlsmith, J., \& Sears, D. (1970). Social psychology.

Englewood Cliffs: Prentice Hall.

Gee, W. (1992). Public and professional attitudes towards AIDS patients. San Francisco: Westview Press.

Goff, W., \& MCDonough. P. (1986). A community health approach to AIDS: Caring for the patient and educating the public. Journal of Community Health Nurse, $3(4), 191-200$.

Harnett, S. (1987). A hospital-wide AIDS education program. Journal of Continuing Education for Nurses. 18(2), 64-67.

Hunter, C., \& Ross, M. (1991). Determinants of healthcare workers' attitudes toward people with AIDS. Journal of Applied Psychology, 21, 947-956.

John, G. (1983). Organizational behavior: Understanding life at work. Dallas: Scott, Foreman and Company.

Kelly, E. (1988). Nurses' attitudes toward AIDS. Journal of Continuing Education in Nursing, 19, 78-83.

Mcllvenna, M. K. (1988). The effect of AIDS education on nurses' knowledge and attitudes in caring for patients with AIDS. Unpublished master's thesis, San Jose State University, San Jose, CA.

Neal, A. (1983). Social psychology. Menlo Park: Addison-Wesley.

Reed, P., Wise, T., \& Mann, L. (1984). Nurses' attitudes regarding acquired immunodeficiency syndrome (AIDS). Nursing Forum, 21(4), 153-156. 
Royse, D., \& Birge, B. (1987). Homophobia and attitudes towards AIDS patients among medical, nursing, and paramedical students. Psychological Reports, 61, 867-870.

Scherer, Y., Yow-Wu, W., \& Haughey, B. (1991). AIDS and homophobia among nurses. Journal of Homosexuality, 21, 17-27.

Schietinger, H. (1986). AIDS education for staff. Journal of Continuing Education for Nurses, 17(7), 3-4.

Schneitz, B. (1992). Patients left out in the cold: Why you may not be covered if you get too sick. Newsweek, p. 48.

Turner, J., McLaughlin, J., \& Shrum, J. (1988). AIDS education: Process, content, and strategies. Health Values, 12, 6-12.

Turner, J. McLaughlin, J., \& Shrum, J. (1988). Nursing and AIDS: Knowledge and attitudes. American Association of Occupational Health Nurse Journal, 36, 274-278.

van Servellen, G., Lewis, C., \& Leake B. (1988): 'Nurses' response to the AIDS crisis: Implications for continuing education programs. Journal of Continuing Education, 19, 9-12.

Wertz, D. C. (1989). Knowledge of attitudes of AIDS healthcare providers before and after education programs. Public Health Reports, 102. 248-254.

White, C. M. (1977). The nurse-patient encounter: Attitudes and behaviors in . action. Journal of Gerontological Nursing, 3,(3), 16-28. 
Williamson, R. C., Swingle, P. G., \& Sargent, S. S. (1986). Social psychology. Itasca, IL: Peacock.

Wilson, H. S. (1989). Research in nursing. Menlo Park: Addison-Wesley.

Witt, A. (1990). Factors affecting attitudes toward persons with AIDS. The Journal of Social Psychology, 139(1), 127-130.

Young, E. W. (1988). Nurses' attitudes toward homosexuality: Analysis of change in AIDS workshops. Journal of Continuing Education in Nursing, 19(1), 9-12. 
APPENDIXES 


\section{APPENDIX A}

\section{Permission Letter}


October 22. 1992

Elizabeth M. Johnson

9 Westport Circle

Salinas, California 93906

Dear Liz,

You have permission to use

as a

site for data collection for your thesis.

I look forward to reviewing your finding with our clinical staff.

Sincerely.

Director of Nursing 


\section{APPENDIX B}

\section{Approval Letter from}

The Human Subjects-Institutional Review Board 
To: Elizabeth Johnson 9363. Bur Oak Place

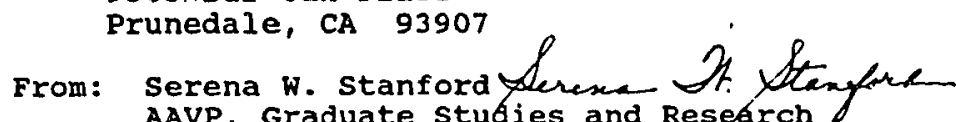
AAVP, Graduate stuaies and Research

Date: March 16, 1993

The Human Subjects-Institutional Review Board has approved your request to use human subjects in the study entitied:

"The Relationship of Knowledge and Attitudes of Home Care Nurses Towards Clients with ArDS"

This approval is contingent upon the subjects participating in your research project being appropriately protected from risk. This includes the protection of the anonymity of the subjects' identity when they participate in your research project, and with regard to any and all data that may be collected from the subjects. The Board's approval includes continued monitoring of your research by the Board to assure that the subjects are being adequately and properly protected from such risks. If at any time a subject becomes injured or complains of injury, you must notify Dr. Serena stanford immediately. Injury includes but is not limited to bodily harm, psychologiral trauma and release of potentially damaging personal information.

Please also be advised that each subject needs to be fully informed and aware that their participation in your research project is voluntary, and that he or she may withdraw from the project at any time. Further, a subject's participation, refusal to participate or withdrawal will not affect any services the subject is receiving or will receive at the institution in which the research is being conducted.

If you have questions, please contact me at 408-924-2480.

CC: Sharon Wahl 
APPENDIX C

Qustionnaire 


\section{QUESTIONNAIRE}

Please circle your response to each question below.

1. Age: $18-20 \quad 21-29 \quad 30-39 \quad 40-49 \quad 50-59 \quad 60-69$

2. Circle your current marital status.

single married separated divorced widowed remarried

living with significant other

3. Please circle your present family status.

I have no children

I am pregnant

I have children

4. Please indicate the number of children you have according to age group and sex.

$$
\text { Daughter Son }
$$

Under 1 year

$1-8$ years

$9-12$ years

13.19 years

20-25 years

Over 26 years

5.1 believe in a religion.

Yes No

Name of religion

6. Circle the highest grade level completed.

$\begin{array}{lllllllllllll}8 & 9 & 10 & 11 & 12 & 13 & 14 & 15 & 16 & 17 & 18 & 19 & 20\end{array}$

7. Circle your present nursing title.

CNA LVN RN 
8. Circle the number of years you have been a nurse.

$$
\text { Less than } 10 \text { years More than } 10 \text { years }
$$

9. I have completed an AIDS education program.

YES NO

10. Type and frequency of contact during work, if any, with AIDS patients.

no contact

unknown contact

less than 5 patients within a year

more than 5 patients a year

11. Type and frequency of contact with family or friends, if any, with AIDS.

no contact

unknown contact

less than 5 persons within a year

more than 5 and less than 25 persons a year

Please circle your response to the following questions.

12. Acquired immunodeficiency syndrome is commonly referred to as AIDS.

True False

13. Human immunodeficiency virus (HIV) is the virus that causes AIDS.

True False

14. San Francisco, Los Angeles, Miami, and New York city are cities reported to have the highest incidence of AIDS cases reported.

True False

15. AIDS patients may not be roomed together. True Fałse

16. One opportunistic infection of AIDS is pneumocystic pneumonia.

True False

17. The use of condoms is an effective barrier against the spread of AIDS.

True

False 
18. When a surface is contaminated with blood, it should be cleaned thoroughly with bleach.

19. Heterosexual women can gel AIDS.

True False

True False

20. The spread of AIDS can be prevented by good handwashing before and after patient care and by wearing gloves when in contact with blood.

True False

21. Needles should not be recapped when being disposed of.

True False

Please indicate your reaction by circling the number which most closely describes your feeling. The scale range is: strongly disagree 1 , disagree 2 , uncertain 3 , agree 4 , strongly agree 5 .

22. I feel caring for AIDS patients should be voluntary.
1
2
3
4
5

23. I would feel comfortable sitting next to or talking to an AIDS patient.
1
2
3
4
5

24. I would take particular care to make a patient with AIDS comfortable.
1
2
3
4
5

25. I would feel comfortable in performing CPR on a patient with AIDS.
$\because \quad 1$
2
3
4
5

26. I am morally offended by people with AIDS.
1
2
3
4
5

27. I would feel comfortable caring for an AIDS patient in the course of my work day.
1
2
3
4
5

28. I would feol comforlable having my relative room with an AIDS patient.
1
2
3
4
5 


\section{APPENDIX D}

Informed Consent Cover Letter 


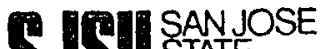

\section{Dear Registered Nurse:}

I need your help in conducting a study of the relationship of knowledge of AIDS to the attitudes of nurses towards patients with AIDS. The results of this study should increase our understanding of the complex relationship between knowledge and attitudes. Altached is a questionnaire asking demographic information, your knowledge of AIDS and your attitudes towards caring for patients with AIDS. Please take a few minutes to complete the form and return it to my mail box.

You should understand that your participation is voluntary and that choosing not to participate in this study, or in any part of this study. will not affect your relations with San Jose State University or

No risks and/or benefits are anticipated by participating in this study.

The result of this study may be published, but any information that could result in your identification will remain confidential.

If you have questions about this study, I will be happy to discuss it with you. I can be reached at (408) 633-2848. Questions or complaints about the research may be presented to the Department Chair (Virgil Parsons, (408) 924-3131). Questions or complaints about research or subjects' rights may be referred to Serena Stanford. Ph. D., Associate Academic Vice President for Graduate Studies and Research , at (408) $924-2480$.

Sincerely,

Elizabeth Manzo Johnson

San Jose State University

Graduate Student 